\title{
Biosimilar Agents for Psoriasis Treatment: The Perspective of Portuguese Patients
}

\author{
Agentes Biossimilares no Tratamento da Psoríase: \\ Perspetiva dos Doentes Portugueses
}

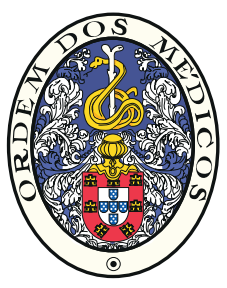

\author{
Alexandra AZEVEDO ${ }^{1}$, Andreia BETTENCOURT ${ }^{2}$, Manuela SELORES ${ }^{1,2}$, Tiago TORRES $\square^{1,2}$ \\ Acta Med Port 2018 Sep;31(9):496-500 - https://doi.org/10.20344/amp.10127
}

\section{ABSTRACT}

Introduction: Biosimilars are highly similar copies of previously approved original biologic medicines. Their introduction on the market may yield cost reduction. The aim of this study was to evaluate the perspectives of psoriasis patients on biosimilar medications.

Materials and Methods: We conducted a 14 questions survey of psoriasis patients receiving biological therapy and followed-up in a dermatology department of a Portuguese tertiary care hospital.

Results: From a total of 108 patients included, $70.4 \%$ of patients did not know the definition of biosimilar agent and $76.6 \%$ of patients showed partial or total interest in using a biosimilar drug. Nearly $80 \%$ of patients partially or totally agreed in using a biosimilar drug in order to reduce healthcare costs with psoriasis treatment. However, the lack of studies in the European population and in psoriatic patients led most of the patients $(72.2 \%$ and $75.0 \%$, respectively) to somewhat or completely oppose to the use of biosimilars. Demographic variables, household income and type of current biologic therapy did not affect patient preferences.

Discussion: Despite of the unfamiliarity of the respondents with biosimilars, most patients seem receptive to their use. Nevertheless, there are two issues of concern: i) the use of biosimilars that are not tested in a European population, and ii) its approval for psoriasis without trials in this disease. Thus, an immediate need exists for patient education about biosimilars.

Conclusion: Biosimilars may increase patient access to biologic therapies. Improved communication and the involvement of patients in decision-making regarding biosimilars may increase their acceptance in future.

Keywords: Biological Therapy; Biosimilar Pharmaceuticals; Psoriasis/therapy

\section{RESUMO}

Introdução: Os agentes biossimilares são cópias muito semelhantes de agentes biológicos originais previamente aprovados. A sua introdução no mercado tem como objetivo reduzir custos. O objetivo deste estudo foi avaliar as perspetivas dos doentes com psoríase sobre os medicamentos biossimilares.

Material e Métodos: Foi realizado um inquérito com 14 questões em doentes com psoríase medicados com agentes biológicos e seguidos num Serviço de Dermatologia de um hospital terciário português.

Resultados: Dos 108 doentes incluídos, 70,4\% desconheciam a definição de agente biossimilar e 76,6\% mostraram interesse parcial ou total no uso de medicamentos biossimilares. Perto de $80 \%$ concordaram com o uso de agentes biossimilares de modo a reduzir os custos associados às terapêuticas biológicas. Contudo, a ausência de estudos na população europeia e em doentes com psoríase levaram a maioria dos doentes $(72,2 \%$ e $75,0 \%$, respetivamente) a oporem-se, parcial ou totalmente, ao uso dos medicamentos biossimilares. Dados demográficos, rendimento mensal e tipo de terapêutica biológica não influenciaram as preferências dos doentes. Discussão: Apesar do desconhecimento dos participantes sobre os medicamentos biossimilares, a maioria dos doentes parece recetiva à sua utilização. Todavia, existem dois motivos de preocupação: i) o uso de medicamentos biossimilares que não foram testados na população europeia, e ii) a sua aprovação para a psoríase sem estudos nesta doença. Assim, é necessário fornecer mais informação aos doentes sobre os medicamentos biossimilares.

Conclusão: Os biossimilares podem aumentar o acesso dos doentes a terapêuticas biológicas. Melhor comunicação e o envolvimento dos doentes na tomada de decisões relativamente aos medicamentos biossimilares pode aumentar a adesão no futuro.

Palavras-chave: Medicamentos Biossimilares; Psoríase/tratamento; Terapia Biológica

\section{INTRODUCTION}

Psoriasis is a chronic inflammatory and immunemediated skin disease with a significant physical and psychological burden. It is estimated to affect 250000 Portuguese patients. ${ }^{1}$

Biologic agents have revolutionized the treatment of psoriasis and psoriatic arthritis, providing an option to patients who were non-responsive to phototherapy and conventional systemic treatments. ${ }^{2}$ However, these therapies impose a heavy burden on the healthcare system due to their high cost. In Portugal, the biologic therapy-related costs are $100 \%$ funded by the national healthcare system.
The expiration of patents and market exclusivity periods of originators allowed the introduction of biosimilars. Biosimilars are defined by European Medicines Agency (EMA) as a 'biological medicinal product that contains a version of the active substance of an already authorised original biological medicinal product (reference product). ${ }^{3}$ In order to be approved by regulatory agencies, biosimilars must prove to be highly structurally analogous to the reference drug and to be highly similar in terms of quality, safety, efficacy and immunogenicity to the originator agent. ${ }^{1}$ Biosimilars may cost $25 \%-30 \%$ less than the original agents, as the

1. Serviço de Dermatologia: Centro Hospitalar do Porto. Porto. Portugal.

2. Instituto de Ciências Biomédicas Abel Salazar. Universidade do Porto. Porto. Portugal.

$\bowtie$ Autor correspondente: Tiago Torres. torres.tiago@outlook.com

Recebido: 21 de dezembro de 2017 - Aceite: 07 de agosto de 2018 | Copyright @ Ordem dos Médicos 2018 
manufacturing process and development costs are considerably lower. Thus, biosimilars are expected to reduce health care costs and to increase patient access to biologic therapies.

Still, some physicians question the quality and safety of biosimilars and express concerns regarding interchangeability and extrapolation of indications. ${ }^{4}$ Regarding patients' perspectives towards biosimilars, many patients with inflammatory bowel disease (IBD) were not familiar with biosimilars, ${ }^{5}$ while safety is the major concern of patients with rheumatoid arthritis (RA) ${ }^{4}$

This study aimed to assess Portuguese psoriasis patients' knowledge about biosimilars, and the factors influencing their preference for originators or biosimilars.

\section{MATERIAL AND METHODS}

We surveyed 108 consecutive Portuguese patients diagnosed with psoriasis and treated with biologic agents in the Dermatology department of Centro Hospitalar do Porto. The survey was conducted from January 1 through July 31,2017 . During this period, all patients evaluated on psoriasis consultation were invited by their dermatologist to participate in this survey. The participants were aged 18 years or older, had a diagnosis of psoriasis and were treated with originator biologic agents. Patients treated with biossimilars medications, phototherapy or oral conventional systemic treatments were excluded. The survey was prepared based on a study of the literature and collaboration with dermatologists. The anonymous questionnaire consisted of 14 closed-ended questions. Regarding the internal validation of the questionnaire, Cronbach's alpha was calculated to evaluate the internal consistency of the responses given by the patients. We assessed demographic data, patients' understanding of biosimilar agents and, after providing a definition, patients' opinion on the introduction of biosimilars. The physician did not provide any information about biosimilars to patients before this survey. The study was approved by the hospital Institutional Review Board and subject's written consent was obtained.

Descriptive statistics from qualitative data was presented as relative frequency per category. Stacked bars were used to show the percentage contribution of the different answers. The one sample chi-squared test was used to evaluate if patients have significantly different opinions in relation to the questions. A univariate logistic regression analysis of the association between the response variable (questions 5 to 9) and each of the demographic variables (age, sex, monthly household income and education) was executed. A multivariate logistic regression model, with stepwise forward selection, was performed only when univariate analysis was $p<0.250$. To perform the logistic regression the dependent variable (patient's answers), were grouped 1- answers a and b, and 2- answers $c$ and d, in order to transform the dependent variable into binary, the answer e (indifferent) was excluded. As for the independent variables, age was used as a continuous variable; education (1- Primary School + Basic school and 2- Secondary school
+ University education) and monthly household income $(1-\leq 530 €$ and $2-531-1060 €+1061-1590 €+>1591 €)$ were grouped. Tests were performed at a significance level of 0.05 . All statistical analysis was performed using SPSS version 24.0 .

\section{RESULTS}

\section{Patients' demographics}

A total of 108 patients participated in this survey. Most patients were male $(65.7 \%)$ and more than half $(52.8 \%)$ of the participants were $40-60$ years of age (Table 1). Most respondents had a monthly household income of less than $1060 €$. Out of 108 psoriatic patients, $10.2 \%$ also had articular

Table 1 - Patient's demographic, economical, clinical and treatment characteristics

\begin{tabular}{|c|c|c|}
\hline \multirow[t]{2}{*}{ Demographics } & \multicolumn{2}{|c|}{$\begin{array}{l}\text { Participants } \\
\qquad(n=108)\end{array}$} \\
\hline & $\mathrm{n}$ & $\%$ \\
\hline \multicolumn{3}{|l|}{ Sex } \\
\hline Female & 37 & 34.3 \\
\hline Male & 71 & 65.7 \\
\hline \multicolumn{3}{|l|}{ Age, years } \\
\hline $18-24$ & 3 & 2.8 \\
\hline $25-39$ & 28 & 25.9 \\
\hline $40-60$ & 57 & 52.8 \\
\hline$>60$ & 20 & 18.5 \\
\hline \multicolumn{3}{|l|}{ Education } \\
\hline Primary school ( $1^{\text {th }}$ to $4^{\text {th }}$ year $)$ & 17 & 15.7 \\
\hline Basic school ( $5^{\text {th }}$ to $9^{\text {th }}$ year $)$ & 27 & 25.0 \\
\hline Secondary school ( $10^{\text {th }}$ to $12^{\text {th }}$ year $)$ & 39 & 36.1 \\
\hline University education & 25 & 23.1 \\
\hline \multicolumn{3}{|l|}{ Monthly household income } \\
\hline$\leq 530 €$ & 43 & 39.8 \\
\hline $531 €-1060 €$ & 43 & 39.8 \\
\hline $1061 €-1590 €$ & 16 & 14.8 \\
\hline$>1591 €$ & 6 & 5.6 \\
\hline \multicolumn{3}{|l|}{ Diagnosis } \\
\hline Psoriasis without articular involvement & 97 & 89.8 \\
\hline Psoriasis with articular involvement & 11 & 10.2 \\
\hline \multicolumn{3}{|l|}{ Duration of biologic treatment } \\
\hline Less than 6 months & 16 & 15.0 \\
\hline Between 6 months and 1 year & 13 & 12.1 \\
\hline Between 1 and 5 years & 62 & 57.9 \\
\hline More than 6 years & 16 & 15.0 \\
\hline \multicolumn{3}{|l|}{ Biologic agent } \\
\hline Adalimumab & 15 & 13.9 \\
\hline Etanercept & 42 & 38.9 \\
\hline Infliximab & 2 & 1.9 \\
\hline Ustekinumab & 25 & 23.1 \\
\hline Secukinumab & 24 & 22.2 \\
\hline
\end{tabular}


involvement. The duration of biologic therapy was between 1 to 5 years for the majority of participants $(57.9 \%)$. The most prescribed biologics were etanercept $(38.9 \%)$ followed by ustekinumab (23.1\%) and secukinumab (22.2\%).

\section{Questionnaire responses}

The Cronbach's alpha for questions five to nine was 0.812 , greater than 0.7 , therefore we can assume that these responses have relatively good internal reliability.

The majority of participants $(70.4 \%)$ did not know what biosimilars were, $24.1 \%$ thought biosimilars were similar but not identical copies of biological medicines, $3.7 \%$ thought they were a new brand of a biological medicine and $1.9 \%$ thought they were an identical copy of a biological medicine. After providing a definition of biosimilar, $76.6 \%$ of participants showed interest (somewhat or very interested) in using a biosimilar, while $15.0 \%$ were against their introduction (Fig. 1) $(p<0.001)$.

Most patients $(80.3 \%)$ showed interest (somewhat or very interested) in using a cheaper biosimilar that can allow for savings to the Portuguese health system. In contrast, $13.2 \%$ of patients disagreed with the use of biosimilar agents even if they allowed a lower expense for the healthcare system (Fig. 1) $(p<0.001)$. If the decision of switching to a cheaper biosimilar comes from the hospital board given the potential cost savings, $79.4 \%$ of participants were in agreement (somewhat or totally) with that decision, while $15.9 \%$ were somewhat or completely against the hospital's decision (Fig. 1) $(p<0.001)$.

Nevertheless, the lack of studies evaluating biosimilars in European patients led $72.2 \%$ of the patients to somewhat or completely oppose to biosimilar agents, while $25.0 \%$ maintained interest in using these drugs (Fig. 1) $(p<$
0.001). Regarding the extrapolation of indications, $75.0 \%$ of participants were partially or completely against the use of a biosimilar approved in psoriasis but only tested in a different pathology. Solely $21.3 \%$ maintained interest in using biosimilars that were approved but not tested in psoriasis (Fig. 1) $(p<0.001)$.

Of the participants, $96.2 \%$ felt that their dermatologist's opinion would somewhat or strongly influence their decision in starting/switching to a biosimilar drug.

Finally, when patients were questioned about the hypothesis of paying for some of the therapy-related costs, $61.7 \%$ of participants were partially or completely interested in switching to a biosimilar agent in order to reduce their own expenses, compared with $31.8 \%$ that expressed some or total interest in keeping the current originator drug (Fig. 2) $(p<0.001)$.

Logistic regression showed that demographics, household income, duration of biologic therapy and current biologic agent did not affect patient's answers $(p>0.05)$.

\section{DISCUSSION}

To our knowledge, this is the first survey addressing the perspectives on biosimilar agents among patients exclusively diagnosed with psoriasis. One of the most noticeable findings was the lack of patient awareness of biosimilars medications. Only $24.1 \%$ of participants were familiar with the biosimilar definition. A previous international cross-sectional survey showed that knowledge on biosimilars was low among patients with several inflammatory and neoplastic diseases, caregivers, and the general population in the US and the European, with only $6 \%-30 \%$ reporting at least a general impression and up to $70 \%$ reporting they had never heard of biosimilars. ${ }^{6}$

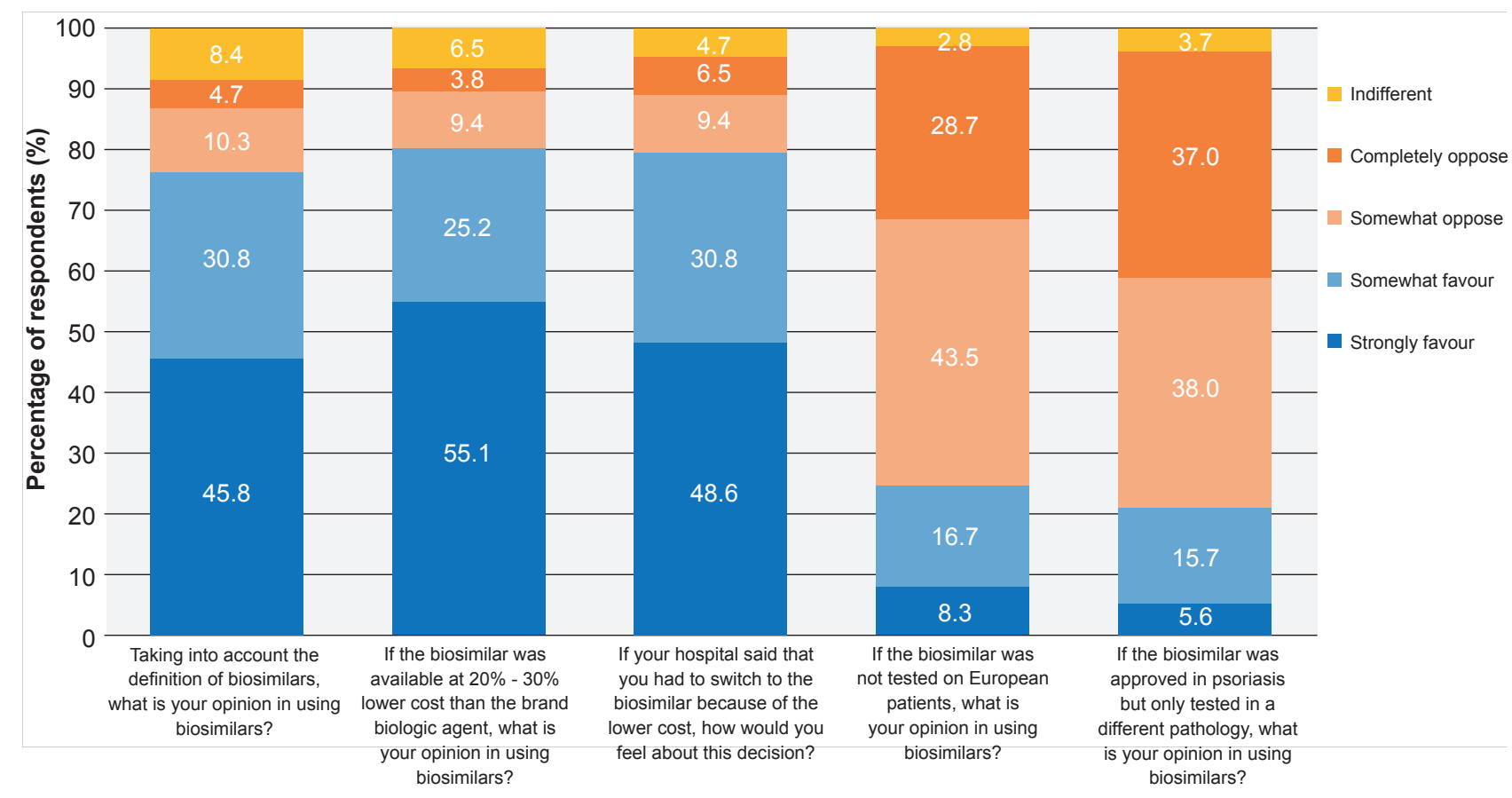

Figure 1 - Patients' answers after providing a definition of biosimilar and regarding factors that might influence them to start/switch to a biosimilar 
If you had to pay for some of the current biologic therapy-related costs, and if the switch to a biosimilar allowed you to pay a lower price, what would be your decision?

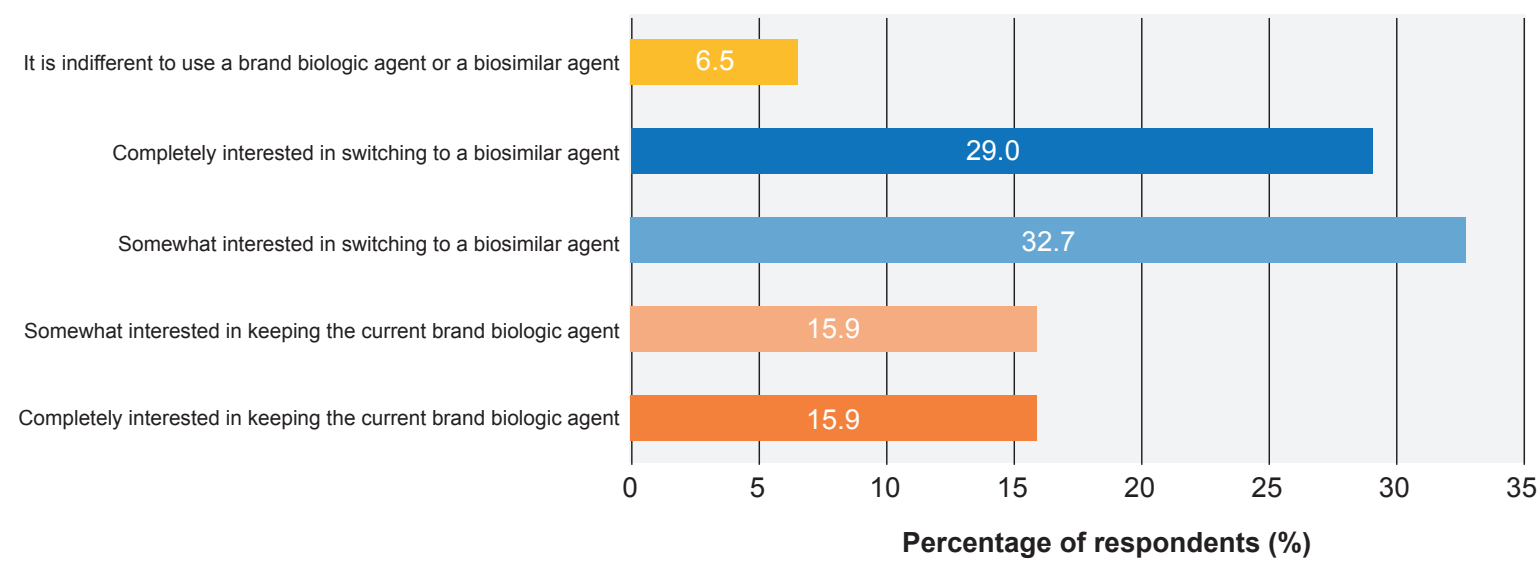

Figure 2 - Patients' answers to the final question regarding the hypothetical scenario of having to pay for some of the therapy-related costs

Lower percentages were also identified in a survey conducted in European patients with IBD: solely $36.6 \%$ of Crohn's disease patients and $35.5 \%$ of ulcerative colitis patients had previously heard of biosimilars. ${ }^{5}$ In Belgian RA patients, $49 \%$ of respondents were familiar with biosimilars. ${ }^{4}$ This highlights a need for patient education about biosimilars in order to ensure informed decision-making.

In our survey, most patients (76.6\%) seemed receptive to using biosimilar agents. Notably, nearly $80 \%$ of patients showed interest in using a biosimilar to reduce healthcare costs with psoriasis treatment, even if the switch was determined by the hospital. This may suggest that patients are conscious about the economic burden of biologic therapy on the healthcare system, and hence are open to the introduction of biosimilars.

Clearly, there are two issues of concern among psoriasis patients: i) the use of biosimilars that are not tested in a European population, and ii) the fact that they are approved for psoriasis but not tested in this disease. Taking this into account, more than $70 \%$ of patients hesitate to use biosimilars. Similar concerns had been reported by IBD patients, as solely $13.1 \%$ of the respondents thought that made sense the use of biosimilars in IBD that were only tested in a different condition made sense. ${ }^{5}$ Many of the raised concerns raised regarding extrapolation may be hypothetical, and likely not problematic in the long term, considering the increasing evidence of efficacy and safety of biosimilars in more than one inflammatory disease. ${ }^{7}$ Further patient education on the various issues regarding biosimilars would possibly clarify these doubts.

Noteworthy, in spite of the above concerns, the possibility of paying some of therapy-related costs seemed to affect patient decision. More than $60 \%$ of participants were receptive to switching to a biosimilar at a lower price if they had to pay for their treatment.

Finally, almost all patients valued their physician's advice to switch to or start a biosimilar. This emphasizes the importance of a good patient-doctor relationship, as depicted in a Belgian survey where $76 \%$ and $65 \%$ of RA patients accepted starting or switching to a biosimilar on their doctor's advice, respectively. ${ }^{4}$

Our study presents some limitations. The selection of participants was limited to psoriasis patients receiving biologic therapy and followed-up in a public dermatology department. Therefore, generalization of findings warrants caution. It would be interesting to evaluate the opinion of patients under other treatments like topical therapy, phototherapy or conventional systemic agents. The relatively low sample size may not allow the identification of associations with statistical significance. The extrapolation concept may be difficult to grasp for a patient with no scientific background, and this should be considered when interpreting the results. Because the complexity of other concepts such as interchangeability and automatic substitution, patients were not specifically asked about their opinion on these topics. Nevertheless, healthcare professionals should provide patients with the necessary information to allow informed decision-making about the use of biosimilars.

\section{CONCLUSION}

Our survey suggests that most psoriatic patients are not familiar with biosimilars and emphasizes the need for further patient education. Most patients seem receptive to using biosimilar agents but are hesitant to use biosimilars not tested in European population and in psoriatic patients. The possibility of paying for some of the therapy-related costs seems to affect patient decision. Physician's advice is important for patient decision. Improved communication and reassurance by dermatologists and the involvement of patients in decision-making regarding biosimilars may increase their acceptance in future.

\section{PROTECTION OF HUMAN AND ANIMAL SUBJECTS}

The authors declare that the research procedures were performed according to the regulations of the institution's ethics committee and the Code of Ethics of the World Medical Association (Declaration of Helsinki). 


\section{CONFIDENTIALITY OF DATA}

The authors declare that they have followed the protocols of their work centre regarding the publication of data from patients.

\section{CONFLICTS OF INTEREST}

Alexandra Azevedo and Andreia Bettencourt have no conflict of interest.

Manuela Selores was an Advisory Board member for Janssen-Cilag,Merck-Serono, Novartis, and Pfizer.

Tiago Torres was a speaker, Advisory Board member and an investigator of observational studies/clinical trials

\section{REFERENCES}

1. Torres T, Filipe P, Selores M. Impact of biosimilars in psoriasis treatment. Acta Med Port. 2013;26:646-8.

2. Torres T, Velho GC, Sanches M, Selores M. Psoriasis in the era of biologics. Acta Med Port. 2010;23:493-8.

3. European Medicines Agency. Guideline on similar biological medicinal products. 2014. [consulted 2017 Dec 7.]. Available from: http://www.ema. europa.eu/docs/en_GB/document_library/Scientific_guideline/2014/10/ WC500176768.pdf.

4. van Overbeeke E, De Beleyr B, de Hoon J, Westhovens R, Huys I. Perception of originator biologics and biosimilars: a survey among belgian rheumatoid arthritis patients and rheumatologists. BioDrugs. supported by: Abbvie, Amgen, Boehringer Ingelheim, Janssen-Cilag, Leo-Pharma, LillyEli, Merck-Serono, Merck Sharp \& Dohme, Novartis, and Pfizer.

The authors have no other relevant affiliations or financial involvement with any organization or entity with a financial interest in or financial conflict with the subject matter or materials discussed in the manuscript, apart from those disclosed.

\section{FOUNDING SOURCE}

None.

\section{7;31:447-59.}

5. Peyrin-Biroulet L, Lonnfors S, Roblin X, Danese S, Avedano L. Patient perspectives on biosimilars: a survey by the European Federation of Crohn's and Ulcerative Colitis Associations. J Crohns Colitis. 2017;11:128-33

6. Jacobs I, Singh E, Sewell KL, Al-Sabbagh A, Shane LG. Patient attitudes and understanding about biosimilars: an international cross-sectional survey. Patient Prefer Adherence. 2016;10:937-48.

7. Torres T, Ferreira A, Ferreira P, Henriques M, Leite L, Magina S, et al Portuguese Position Paper on the Use of Biosimilars in Psoriasis. Acta Med Port. 2016;29:574-7. 